\title{
Ruptured Heterotopic Pregnancy: A Rare Encounter in Acute Surgical Care Settings
}

\author{
Amro Elhadidi ${ }^{1}$, Abdelrazak Alhariri ${ }^{2}$, Mohamed Hosny Garib ${ }^{2}$, Ahmed Mansour ${ }^{2}$, Bandar Almutiri ${ }^{2}$
}

1. Surgery, Mansoura Univeristy, Mansoura, EGY 2. Surgery, Buriadah Central Hospital, Buriadah, SAU

Corresponding author: Amro Elhadidi, amroshawki@gmail.com

\begin{abstract}
Heterotopic pregnancy is a rare, life-threatening clinical entity with an overall incidence of about 1:30,000 in spontaneous natural conception cases, especially in cases of delayed diagnosis or conflicting clinical features. Here, we present an unusual case of heterotopic pregnancy in a 22-year-old multigravida presented to the emergency department (ED) with a clinical picture of the acute abdomen following recent abdominal trauma. Abdominal ultrasound revealed hemoperitoneum and a single viable intrauterine pregnancy at seven weeks' gestation. Following surgical exploration, the patient underwent removal of the ectopic pregnancy tissue with right salpingectomy. Since the presence of a conflicting history or equivocal physical signs and symptoms makes it difficult to diagnose heterotopic pregnancy, ED physicians and surgeons must consider the diagnosis even when dealing with viable intrauterine pregnancies. Besides, acute abdominal pain associated with shock should be regarded as suggestive of heterotopic pregnancy. Thus, prompt evaluation and a high index of suspicion are of paramount importance to prevent unwanted sequelae.
\end{abstract}

Categories: Emergency Medicine, Obstetrics/Gynecology, General Surgery

Keywords: heterotopic pregnancy, ectopic pregnancy, salpingectomy, hemorrhagic shock

\section{Introduction}

Heterotopic pregnancy is a rare gynecological entity characterized by simultaneous intrauterine and extrauterine pregnancies [1]. The incidence of heterotopic pregnancy, which is estimated at about 1:7,000 to 1:50,000 pregnancies in the general population, has been reported to be $0.09 \%$ to $1.00 \%$ of pregnancies when using assisted fertilization techniques [2-5].

Review began $11 / 16 / 2020$ Review ended 11/22/2020 Published 11/30/2020

(c) Copyright 2020

Elhadidi et al. This is an open access article distributed under the terms of the Creative Commons Attribution License CC-BY 4.0., which permits unrestricted use, distribution, and reproduction in any medium, provided the original author and source are credited.
The risk factors associated with heterotopic pregnancy may include pelvic inflammatory disease, previous history of ectopic pregnancies, personalized assisted fertilization, and ovarian hyperstimulation with increase in the risk of abortion with an estimated odd ratio of $3.948[6,7]$.

Heterotopic pregnancy has a wide variety of clinical presentations, ranging from slight abdominal pain with nausea and vomiting to hemorrhagic shock with or without evidence of adnexal mass rupture [2,7]. Hence, ED physicians and acute care surgeons should maintain a high index of suspicion for this fatal condition to allow for accurate early diagnosis and proper management [8].

Herein, we present a case of heterotopic pregnancy in a patient who had a vague history of recent abdominal trauma without any risk factors, whose initial diagnosis was difficult to make

\section{Case Presentation}

A 22-year-old multigravida presented to the emergency department (ED) with dizziness, vomiting, and diffuse abdominal pain at seven weeks of gestation. Her past medical history only included mild blunt abdominal trauma two days ago by her son. There was no history of vaginal bleeding. On the ED initial examination, the patient had stable vital signs and routine blood work. After a few hours, the ED called the surgical team to re-evaluate the patient's sudden hemodynamic instability. The clinical review revealed a confused patient with tachycardia and hypotension $(85 / 40 \mathrm{mmHg})$. Abdominal examination revealed a distended and tender abdomen. Consequently, we initiated fluid resuscitation with lactated Ringer's solution and ordered adequate cross-matched blood. Abdominal ultrasound (US) revealed marked free fluid in the peritoneal cavity (Figure 1). 


\section{Cureus}

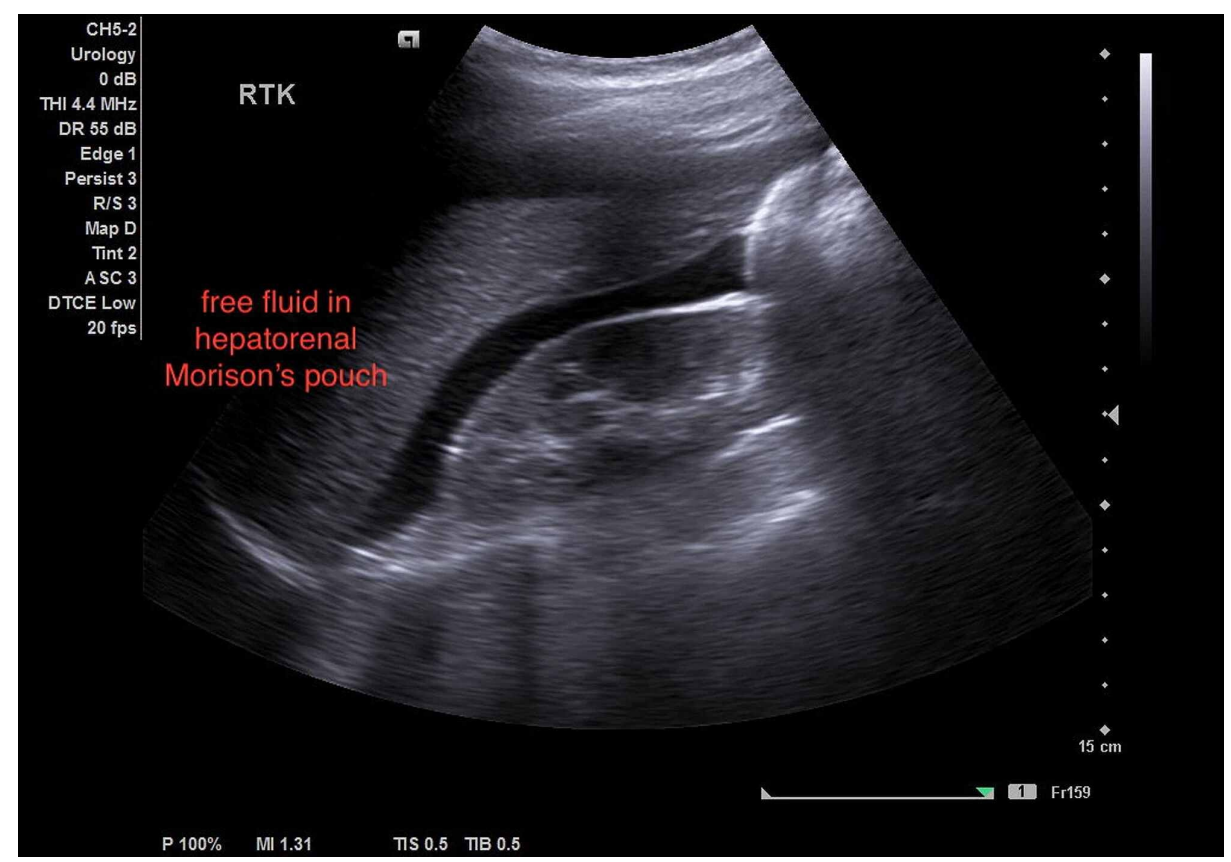

FIGURE 1: Abdominal US showed free fluids in the peritoneal cavity

A single viable intrauterine fetus associated with an area of heterogonous echo pattern mass related to the right adnexa surrounded by fluid collection was also evident by sonographic examination, suggesting the possibility of heterotopic pregnancy (Figure 2).

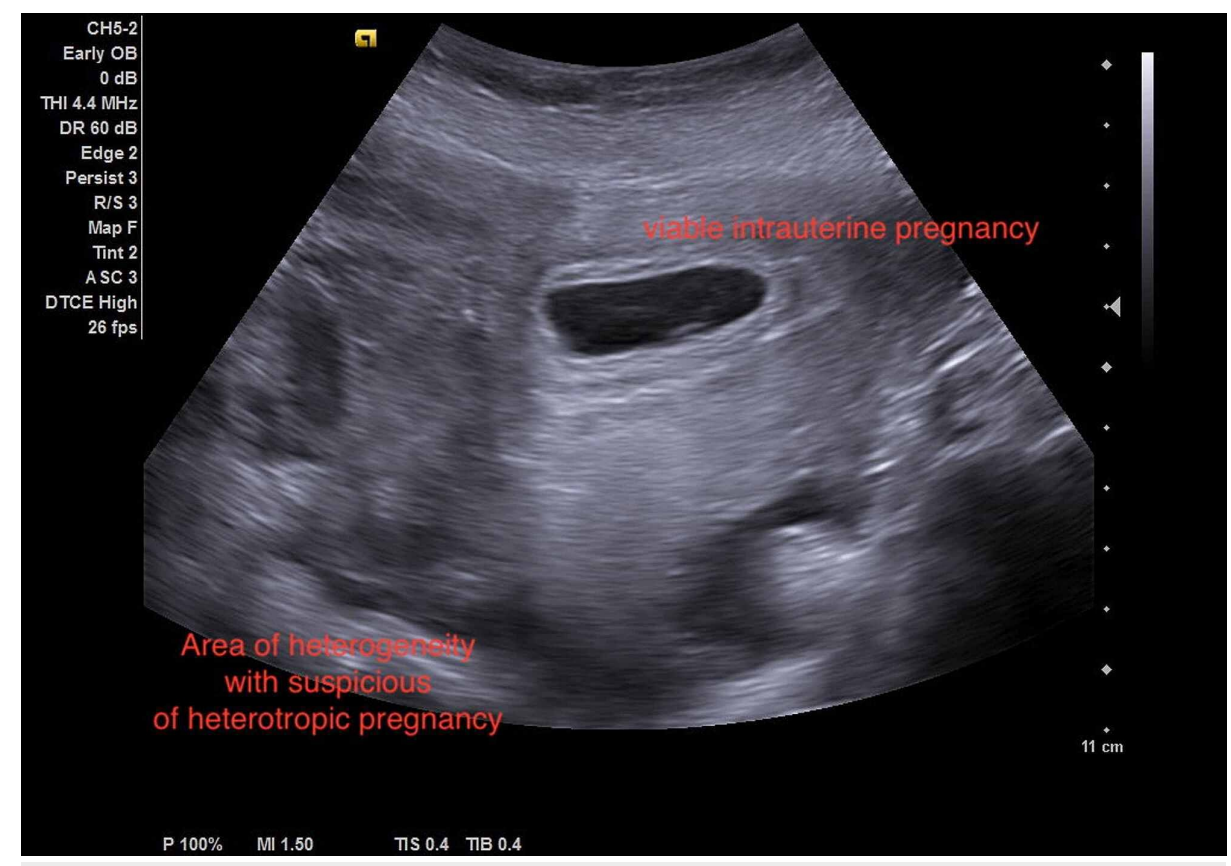

FIGURE 2: The preoperative US showed a single viable intra-uterine fetus and the heterogeneous area, which raise the suspicious of heterotopic pregnancy

We opted for immediate diagnostic exploration instead of transferring her to a maternity hospital, given the patient's hemodynamic instability. Intraoperative findings were indicative of marked hemoperitoneum and right-sided ruptured ectopic pregnancy (Figure 3). 


\section{Cureus}

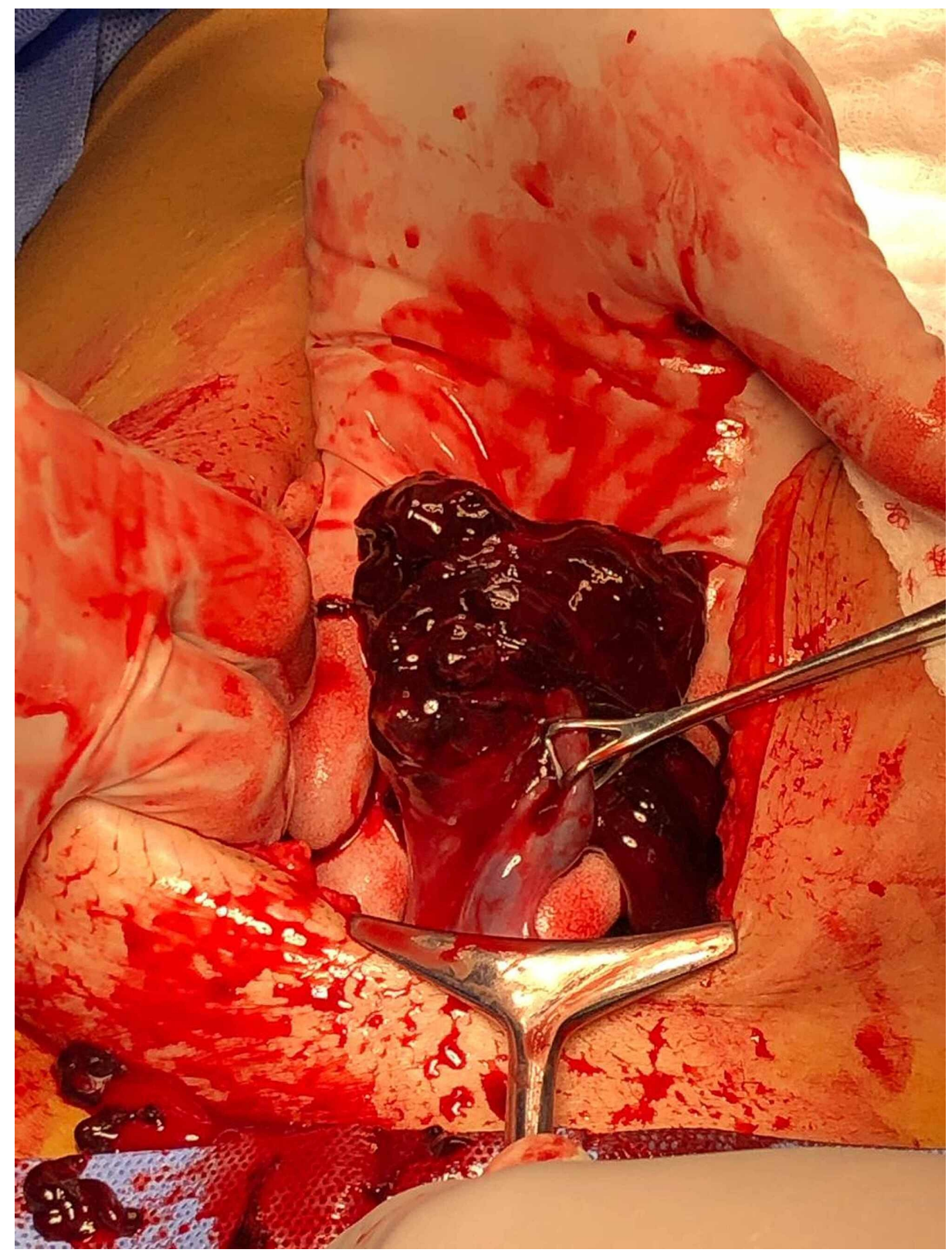

FIGURE 3: Surgical exploration with evident right-sided ruptured ectopic pregnancy

We decided to perform the right salpingectomy with adequate peritoneal lavage (Figure 4). 


\section{Cureus}

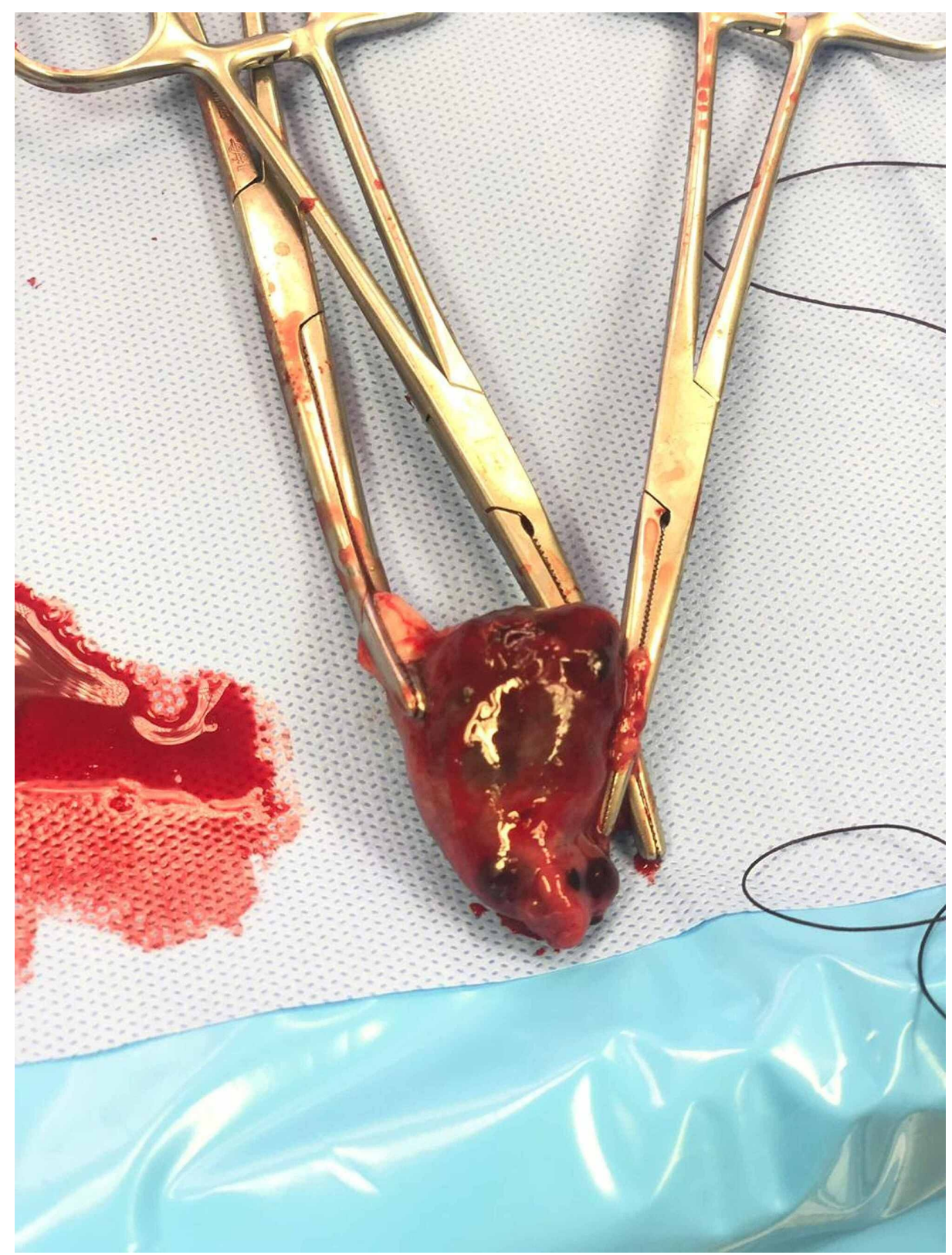

FIGURE 4: Right salpingectomy specimen along with the ectopic pregnancy tissue

The patient had an uneventful recovery and was discharged five days after surgery without any complications (Figure 5). 


\section{Cureus}

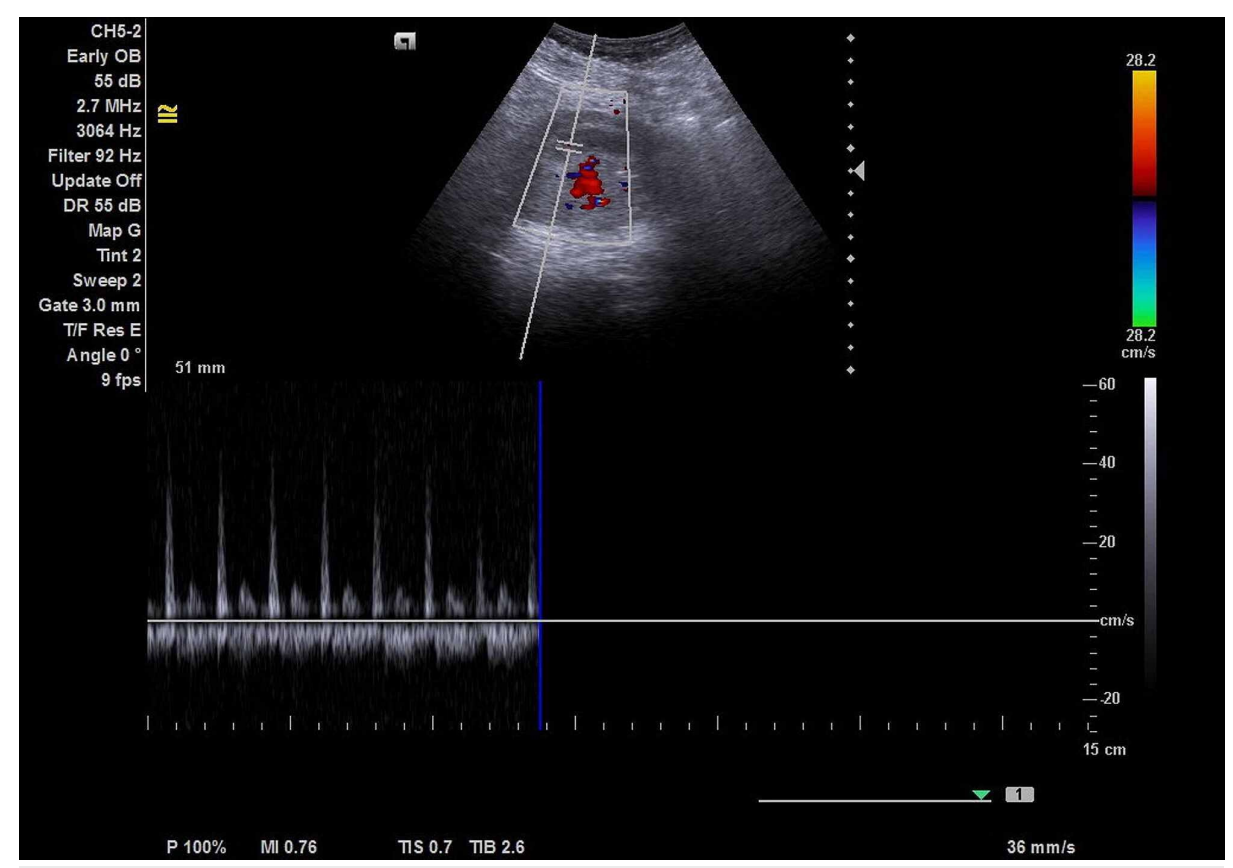

\section{FIGURE 5: The abdominal US showed fetal heart rate in viable intra- uterine fetus during the early postoperative period.}

Postoperative histological examination of the specimen confirmed the diagnosis of ruptured ectopic pregnancy. Finally, the patient was followed up in the surgical outpatient clinic and attended regular obstetric follow-up sessions until safe delivery.

\section{Discussion}

Ruptured heterotopic pregnancy is a rare obstetric emergency that may be difficult for inexperienced physicians to diagnose and therefore requires a high index of suspicion. Up to $70 \%$ of heterotopic pregnancies can be detected between five to eight weeks of gestation [9]. With the growing popularity of assisted reproductive technology and ovarian hyperstimulation, more patients with heterotopic pregnancy present to emergency care settings, most probably due to the increased hydrostatic pressure during embryo transfer [1,10-12].

Our patient had none of the predisposing factors for heterotopic pregnancy but reported a conflicting history of blunt abdominal trauma, which misled the attending ED physician who treated the patient's complaints as expected early pregnancy symptoms. The right adnexal heterogenous mass alongside peritoneal free fluid and intact solid organs excluded that conflicting history on abdominal US examination. In such cases, high-resolution transvaginal US combined with color Doppler can be used as an excellent diagnostic tool because it produces a better visualization of the trophoblastic tissue with typically high flow and low resistive indices. Although this imaging modality is recommended for high-risk patients, particularly those in early pregnancy, its specificity ranges from $26.3 \%$ to $92.4 \%[9,13,14]$.

Many conditions can mimic heterotopic pregnancy - especially when examined by US - such as intrauterine pregnancy associated with corpus luteum cysts, hemorrhagic cysts, and bicornuate uterus gestation. Other acute diseases, like acute appendicitis and cholecystitis, in pregnancy, can also delay the diagnosis [15].

The timing of the onset and presentation of symptoms largely determine the modality of treatment for heterotopic pregnancy. While pharmacological interventions (e.g., potassium chloride or hyperosmolar glucose) and ultrasound-guided interventions can be undertaken in stable patients, surgical intervention represents the most adopted and effective therapy for heterotopic pregnancy [16,17]. The surgical options in emergency settings include salpingectomy, salpingotomy, oophorectomy, or (on rare occasions) hysterectomy [18].

Furthermore, the surgical team can employ either an open or laparoscopic approach depending on the patient's clinical status, surgeon's experience, and surgical instrument availability. Both of these approaches can lead to favourable postoperative outcomes with minimal morbidity. In the presented case, we urge open exploration due to the patient's hemodynamic instability aiming to save the mother's life and viable fetus. Right salpingectomy with minimal manipulation of the gravid uterus was adequate for bleeding control. The cooperation between the surgeons and obstetricians was present from the patient diagnosis and during the 
patient's follow-up in the postoperative period, which undoubtedly led to a better outcome.

\section{Conclusions}

The current report is a unique example describing how much patient history can be conflicting for the examining physicians and can delay the diagnosis. Also, while heterotopic pregnancy is rare, acute care surgeons must consider the diagnosis during pregnancy, significantly if associated with acute abdomen.

\section{Additional Information}

\section{Disclosures}

Human subjects: Consent was obtained by all participants in this study. Conflicts of interest: In compliance with the ICMJE uniform disclosure form, all authors declare the following: Payment/services info: All authors have declared that no financial support was received from any organization for the submitted work. Financial relationships: All authors have declared that they have no financial relationships at present or within the previous three years with any organizations that might have an interest in the submitted work. Other relationships: All authors have declared that there are no other relationships or activities that could appear to have influenced the submitted work.

\section{References}

1. Hassani KM, Bouazzaoui AE, Khatouf M, Mazaz K: Heterotopic pregnancy: a diagnosis we should suspect more often. J Emerg Trauma Shock. 2010, 3:304. 10.4103/0974-2700.66563

2. Felekis T, Akrivis C, Tsirkas P, Korkontzelos I: Heterotopic triplet pregnancy after in vitro fertilization with favorable outcome of the intrauterine twin pregnancy subsequent to surgical treatment of the tubal pregnancy. Case Rep Obstet Gynecol. 2014, 2014:356131. 10.1155/2014/356131

3. Jan F, Naikoo GM, Rather MH, Sheikh TA, Rather YH: Ruptured heterotopic pregnancy: a rare cause for hemoperitoneum; report of three cases from Kashmir, India. Indian J Surg. 2010, 72:404-406. 10.1007/s12262-010-0098-0

4. Shetty SK, Shetty AK: A case of heterotopic pregnancy with tubal rupture . J Clin Diagn Res. 2013, 7:30003001. 10.7860/TCDR/2013/7526.3826

5. Oral S, Akpak YK, Karaca N, Babacan A, Savan K: Cornual heterotopic pregnancy after bilateral salpingectomy and uterine septum resection resulting in term delivery of a healthy infant. Case Rep Obstet Gynecol. 2014, 2014:157030. 10.1155/2014/157030

6. Fatema N, Al Badi MM, Rahman M, Elawdy MM: Heterotopic pregnancy with natural conception; a rare event that is still being misdiagnosed: a case report. Clin Case Rep. 2016, 4:272-275. 10.1002/ccr3.502

7. Jeon JH, Hwang YL, Shin IH, Park CW, Yang KM, Kim HO: The risk factors and pregnancy outcomes of 48 cases of heterotopic pregnancy from a single center. J Korean Med Sci. 2016, 31:1094-1099. 10.3346/jkms.2016.31.7.1094

8. Levi CS, Lyons EA, Dashefsky SM: First trimester ultrasound. Diagnostic Ultrasound. CRC Press, Boca Raton; 2008. 1016-1047. 10.1201/9780429195358

9. Talbot K, Simpson R, Price N, Jackson SR: Heterotopic pregnancy. J Obstet Gynaecol. 2011, 31:7-12. 10.3109/01443615.2010.522749

10. Umranikar S, Umranikar A, Rafi J, Bawden P, Umranikar S, O'Sullivan B, Moors A: Acute presentation of a heterotopic pregnancy following spontaneous conception: a case report. Cases J. 2009, 2:9369. 10.1186/1757-1626-2-9369

11. Tal J, Haddad S, Gordon N, Timor-Tritsch I: Heterotopic pregnancy after ovulation induction and assisted reproductive technologies: a literature review from 1971 to 1993. Fertil Steril. 1996, 66:1-12. 10.1016/s00150282(16)58378-2

12. Lin EP, Bhatt S, Dogra VS: Diagnostic clues to ectopic pregnancy. Radiographics. 2008, 28:1661-1671. 10.1148/rg.286085506

13. Glassner MJ, Aron E, Eskin BA: Ovulation induction with clomiphene and the rise in heterotopic pregnancies. A report of two cases. J Reprod Med. 1990, 35:175-8.

14. Sohail S: Hemorrhagic corpus luteum mimicking heterotopic pregnancy . J Coll Physicians Surg Pak. 2005, 15:180-181.

15. Li JB, Kong LZ, Yang JB, Niu G, Fan L, Huang JZ, Chen SQ: Management of heterotopic pregnancy: experience from 1 tertiary medical center. Medicine. 2016, 95:2570. 10.1097/MD.0000000000002570

16. Lang PF, Weiss PAM, Mayer HO, Haas JG, Hönigl W: Conservative treatment of ectopic pregnancy with local injection of hyperosmolar glucose solution or prostaglandin-F2 $\alpha$ : a prospective randomised study. Lancet. 1990, 336:78-81. 10.1016/0140-6736(90)91593-Y

17. Goldstein JS, Ratts VS, Philpott T, Dahan MH: Risk of surgery after use of potassium chloride for treatment of tubal heterotopic pregnancy. Obstet Gynecol. 2006, 107:506-508. 10.1097/01.AOG.0000175145.23512.5e

18. Ciebiera M, Słabuszewska-Jóźwiak A, Zaręba K, Jakiel G: Heterotopic pregnancy - how easily you can go wrong in diagnosing? A case study. J Ultrason. 2018, 18:355-358. 10.15557/jou.2018.0052 